\title{
Vehnä viljelyvaihtoehdoksi Pohjois-Pohjanmaalla?
}

\author{
Essi Saarinen ${ }^{1)}$ ja Raija Suomela ${ }^{2)}$ \\ ${ }^{1)}$ MTT Ruukki, Tutkimusasemantie 15,92400Ruukki, essi.saarinen@mtt.fi \\ ${ }^{2)}$ MTT Ruukki, Tutkimusasemantie 15, 92400 Ruukki, raija.suomela@mtt.fi
}

\section{Tiivistelmä}

Pohjois-Pohjanmaalla suositaan rehuviljan viljelyssä ohraa ja kauraa, mutta vehnä voisi olla kannattavampi vaihtoehto ohran intervention sulkeutuessa. MTT Ruukissa on testattu kolmen vuoden aikana vehnän viljelyvarmuutta ja sadontuottokykyä. Käytännössä on osoittautunut, että lujakortinen vehnä kestää viljelyssä tehokkaan karjanlannan käytön, jolloin korkeaa valkuaispitoisuutta on mahdollista tavoitella kustannustehokkaasti. Vehnää ei ole testattu IV -vyöhykkeen virallisissa lajikekokeissa.

Vehnän viljely on tulosten perusteella mahdollista joskin riskialtista Pohjois-Pohjanmaalla. Keskimääräinen kasvukausi lämpötilaltaan ja sateiltaan riittää todennäköisesti aikaisimpien lajikkeiden sadonmuodostukselle niin, että sadosta saadaan kauppakelpoista rehuvehnää. Myöhäisemmille lajikkeille kasvukauden tulee olla jo selkeästi alueen normaalia kasvukautta lämpimämpi ja pitempi, etenkin sadon laadun varmistamiseksi.

Tämän koesarjan perusteella kannattaa ottaa viljelyyn kaikkein aikaisimpia lajikkeita PohjoisPohjanmaalla ja esimerkiksi vain tietylle osalle tilan peltolohkoista. Kokeiden vehnälajikkeista Anniina oli viljelyvarmin. Siitä saatiin keskimäärin yli 5000 kilon hehtaarisato ja hehtolitrapaino oli keskimäärin yli 74 kiloa. Alueella käytännön viljelyssä suositusta Quarnasta saatiin keskimäärin 4700 kilon hehtaarisato, mutta hehtolitrapainot jäivät keskimäärin 71 kiloon. Aikaisten lajikkeiden tautitorjunnalla oli yleensä satovastetta, jos tauteja esiintyi runsaasti ja kasvuolosuhteet olivat hyvät. Valkuaispitoisuudet olivat kaikkina vuosina merkitsevästi riippuvaisia lajikkeesta. Vuosina 2007 ja 2009 valkuaispitoisuudet ylittivät yleensä teollisuuden 12,5\% vaatimusrajan. Heikompilaatuiselle vehnälle löytyy myös myyntikanava. Se soveltuu karjan rehuksi, koska on ruokinnalliselta laadultaan suunnilleen ohran tasoista.

Uudet aikaiset jalostuslinjat osoittautuivat vuonna 2009 viljelyvarmoiksi. Niiden testaus jatkossa pohjoisemmissa olosuhteissa olisi erittäin tärkeää, sillä aikaiset lajikkeet ovat edellytys vehnän viljelyyn IV-kasvillisuusvyöhykkeellä. 


\section{Kokeen toteutus}

Kokeet suoritettiin Ruukissa ja Limingassa vuosina 2007-2009. Koelajikkeiksi valittiin kasvuajaltaan aikaisimpia vehnälajikkeita. Molempien koepaikkojen pellot olivat alueelle tyypillisiä karkeita hietamaita (KHt), pH arvot olivat 6,5-7,5 välillä.

Kokeet lannoitettiin ympäristötuen ohjeiden mukaan ja koealueille tehtiin rikkakasvitorjunta. Kokeissa testattiin tautiaineitten vaikutusta vehnän sato- ja laatutuloksiin. Vuonna 2007 tehtiin Proline -tautiainetorjunta käyttömäärillä 0 ja $0,5 \mathrm{l} \mathrm{ha}^{-1}$. Vuonna 2008 kokeessa laajennettiin Proline -aineen käyttömääriä 0 ja $0,5 l$ ha $^{-1}$ lisäksi 0,81 ha $^{-1}$. Vuonna 2009 tautiaineena oli Stratego, käyttömäärillä 0 ja $0,8 \mathrm{l} \mathrm{ha}^{-1}$.

\section{Sääolosuhteiden vaikutus viljan kehitykseen}

Vuonna 2007 kasvukausi oli lämmin ja sateinen. Lajikkeilla oli odotetusti merkitsevä vaikutus vehnän kasvuaikaan ja kasvin kasvun vaativaan lämpösummaan. Lajikkeista aikaiset, Anniina (virallisten lajikekokeiden perusteella kasvuaika 99,3 pv) ja Aino (100,1 pv), tuleentuivat vuonna 2007 Ruukissa ja Limingassa noin 103-105 päivässä.

Vuoden 2008 keskilämpötilat olivat vertailujakson keskilämpötiloja matalammat koko kesän ajan ja sadetta kertyi runsaasti etenkin kesä- ja heinäkuussa. Kylmänä vuonna esimerkiksi kokeen aikaisimman Anniina -lajikkeen kasvuaika oli 128 päivää ja vehnä pakkotuleentui. Vuonna 2009 lämpösummaa kertyi lähes 1200 astetta (Kuva 1.) ja aikaisimmat lajikkeet tarvitsivat tuleentuakseen noin 101 päivää. Alueella hyvin suosittu, hieman Anniinaa myöhäisempi Quarna -lajike käytti kokeessa vuonna 2007 104,5 päivää tuleentuakseen. Virallisten lajikekokeiden perusteella sen kasvuajaksi on määritetty 101,3 päivää. Vuonna 2008 lajike ei tuleentunut ja puitiin yli 130 kasvupäivän jälkeen. Lämpimänä vuonna 2009 Quarnan tulentumiseen riitti Limingassa keskimäärin 101,7 päivää.

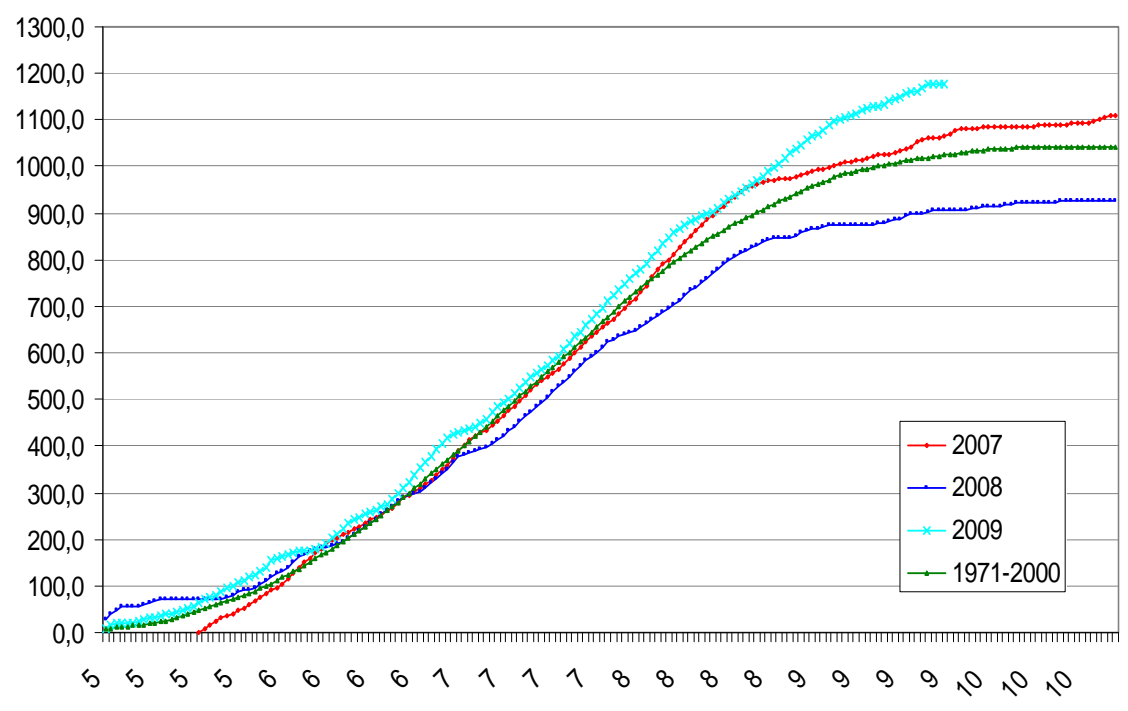

Kuva 1. Ruukissa kertyneet lämpösummat vuosilta 2007-2009 sekä keskiarvo vuosilta 1971-2000.

\section{Rehuvehnä tuleentuu Pohjois-Pohjanmaalla sääoloiltaan normaalina kasvukautena}

Tulosten perusteella aikaiset vehnälajikkeet soveltuvat viljelyyn IV -kasvillisuusvyöhykkeelle, mutta eivät aivan riskittömästi. Vuonna 2007 kokeessa olivat mukana Aino-, Anniina-, Bjarne-, Kruunu- ja Quarna-lajikkeet sekä Boreal Kasvinjalostus Oy:n jalostuslinjat Bor02012, Bor03041, ja Bor03517. Hehtaarisadot (Kuva 2.) olivat kaikilla lajikkeilla vuonna 2007 suuremmat kuin mitä virallisissa lajikekokeissa viljelyvyöhykkeillä I-III on yleensä ollut (Kangas ym. 2008). Kasvukausi olikin suhteellisen lämmin ja pitkä. 
Limingassa satoisimmat lajikkeet olivat Quarna ja Bjarne, joiden keskimääräinen sato oli 5500 $\mathrm{kg} \mathrm{ha}^{-1}$. Ruukissa satoisin vehnälajike oli Aino, josta saatiin satoa torjutuista kasvustoista noin $6800 \mathrm{~kg}$ $\mathrm{ha}^{-1}$ ja torjumatta jätetyistä kasvustoista $6350 \mathrm{~kg} \mathrm{ha}^{-1}$. Lajikkeista vähäsatoisin oli Bor03517, jonka sato Limingassa oli vain keskimäärin 4700 ja Ruukissa noin 5600 (ei torjuntaa) - 6100 (torjunta) kg $\mathrm{ha}^{-1}$. Teollisuuden hehtolitrapainokriteerin (72 kg) täyttivät vuonna 2007 lajikkeet Anniina ja Quarna.

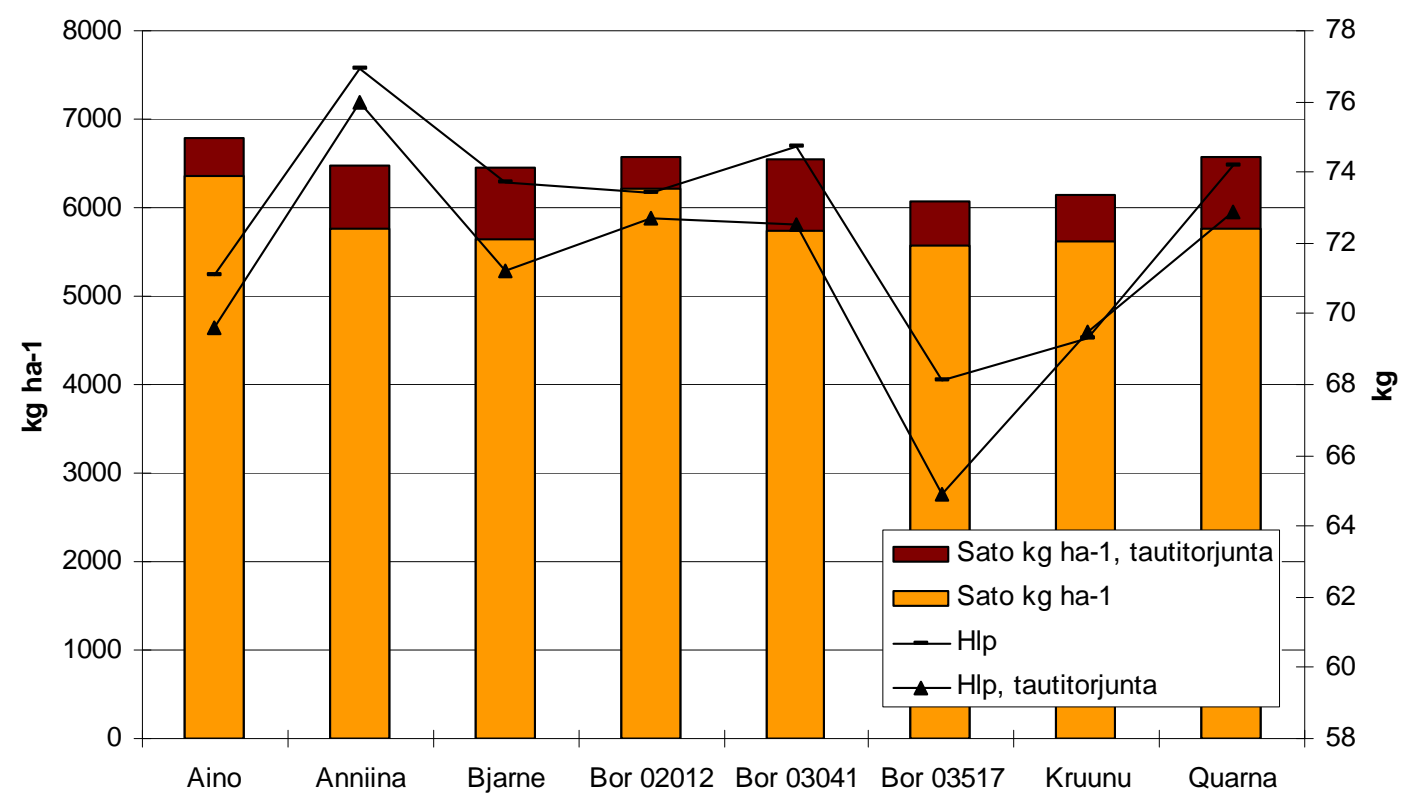

Kuva 2. Kevätvehnän lajikekokeen sato- ja hehtolitrapainotulokset Ruukissa vuonna 2007.

Erikoisen kylmä ja sateinen kasvukausi vuonna 2008 oli vehnän viljelyn kannalta haasteellinen Pohjois-Pohjanmaalla. Vuonna 2008 lajikkeista mukana olivat Aino, Anniina, Bjarne, Kruunu ja Quarna. Kasvustojen pakkotuleentuminen heijastui sato- ja sadonlaatutuloksiin (Kuva 3.) etenkin kokeen myöhäisimmillä lajikkeilla. Kokeessa lajikkeista kasvuajaltaan aikaisimmasta Anniinasta saatiin selkeästi parhaimmat sato- ja laatutulokset, keskimäärin yli 5000 kg hehtaarisato, mutta hl painot (Liminka noin 65, Ruukki noin 70) jäivät teollisuuden laatuvaatimuksista. Muut lajikkeet ylsivät keskimäärin lähes 4500 kg/ha satoihin mutta vain 57-66 hehtolitrapainoihin.

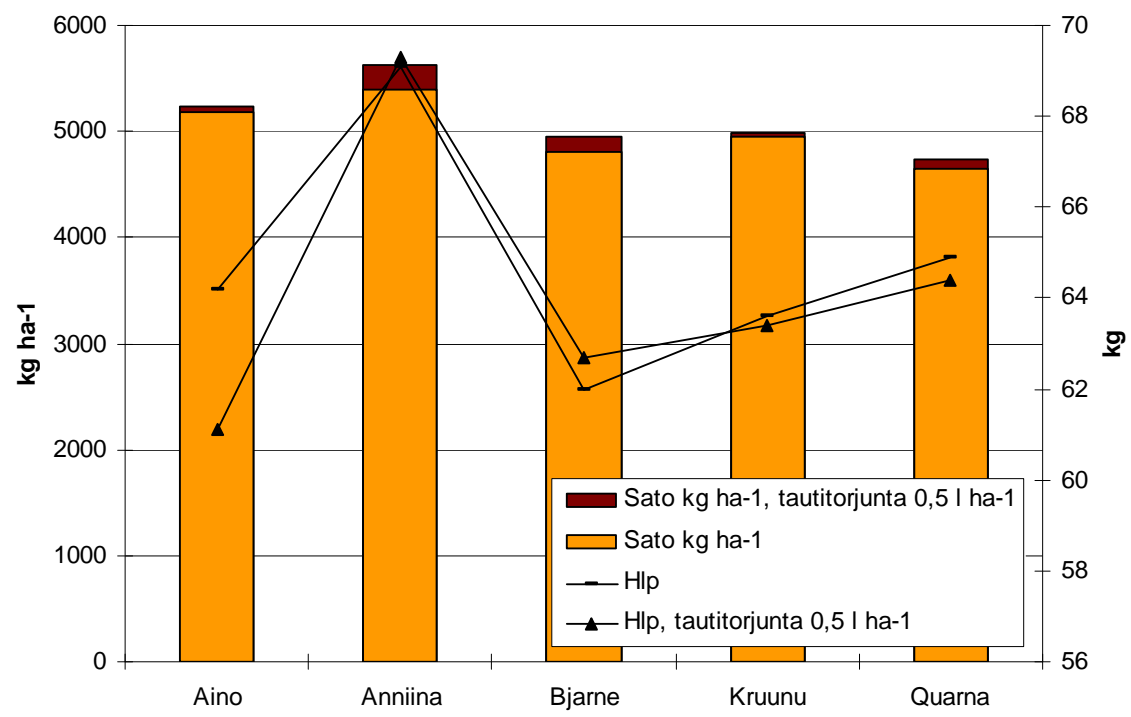

Kuva 3. Kevätvehnän lajikekokeen sato- ja hehtolitrapainotulokset Ruukissa vuonna 2008. 
Vuosi 2009 oli Pohjois-Pohjanmaalla pitkän aikavälin keskiarvoa lämpimämpi ja lämpösummaa kertyi syyskuun loppuun mennessä lähes 1200 astetta. Kasvukausi ei ollut kuitenkaan vehnälle optimaalinen, sillä kuivuus vaivasi kasvustoja varsinkin keväällä ja kasvustoruiskutusten aikaan. Vuonna 2009 kokeessa olivat mukana Anniina-, Berserk-, Quarna -lajikkeet sekä jalostuslinjat Bor03026 ja Bor04086. Aikaisten lajikkeiden ja lupaavien linjojen satotasot (Kuva 4.) olivat noin 5 000 kg/ha ja ne saavuttivat 80 kilon hehtolitrapainon. Myöhäisemmät lajikkeet Quarna ja Berserk eivät pärjänneet olosuhteissa yhtä hyvin, mutta tuottivat kaikki yli 3000 kilon hehtaarisadot sekä Ruukissa että Limingassa. Hehtolitrapainot jäivät aikaisten lajikkeiden painoja hieman alhaisemmiksi noin 78 kiloon.

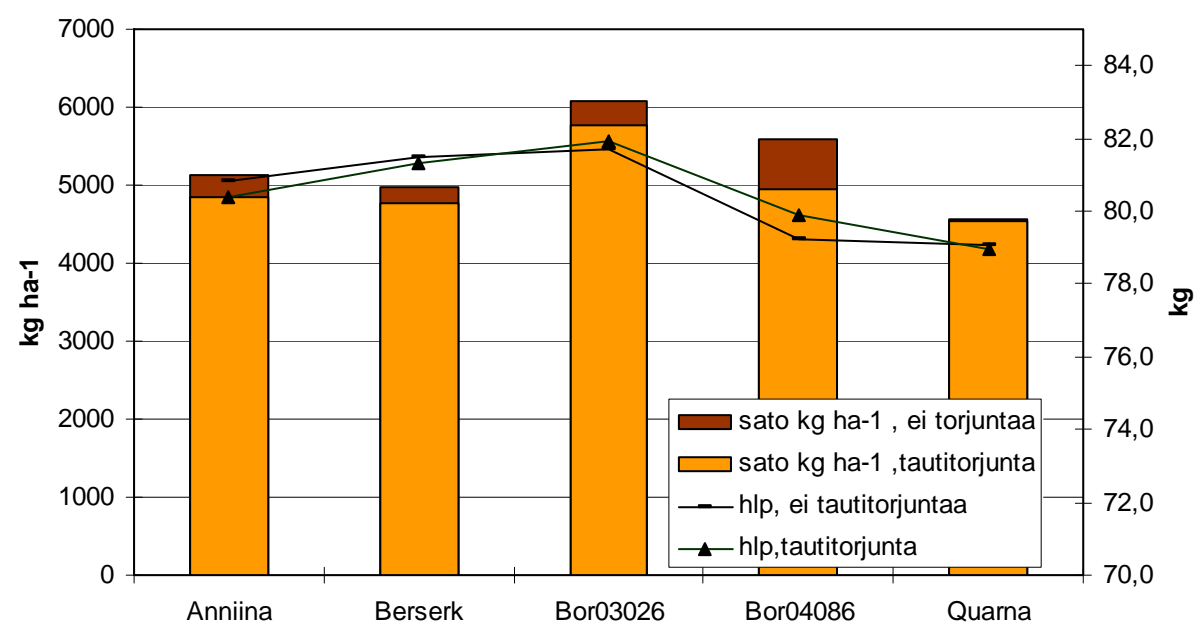

Kuva 4. Kevätvehnän lajikekokeen sato- ja hehtolitrapainotulokset Ruukissa vuonna 2009.

Uudet kasvuajaltaan aikaiset jalostuslinjat erottuivat kokeissa positiivisesti. Molemmista, Bor03026 ja Bor04086, saatiin Anniinaa korkeammat sadot ja hehtolitrapainot (Kuva 5). Uusien linjojen menestymisen osasyynä oli varmasti voimakas kasvuun lähtö keväällä, sillä keväällä vahvaksi kehittynyt juuristo mahdollisti vahvan kasvun kesällä huolimatta kuivista olosuhteista.

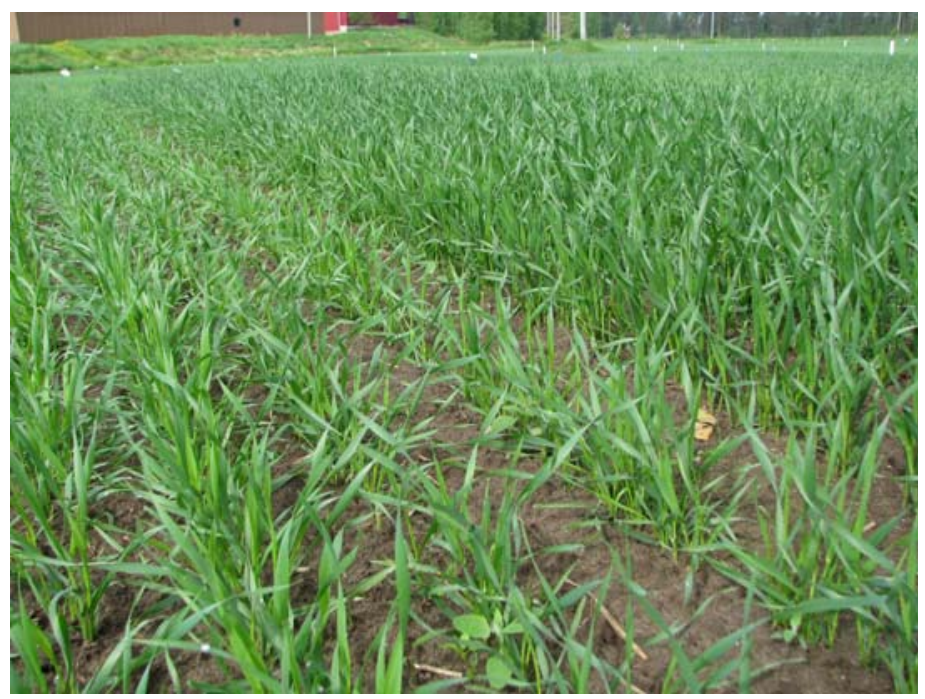

Kuva 5. Aikainen linja Bor 03026(oikealla) lähti keväällä 2009 vahvaan kasvuun. Vasemmalla aikainen lajike Anniina. Kuva otettu Ruukin koelohkolta.

\section{Mahdollisuus leipävehnän tuottoon?}

Valkuaispitoisuudet olivat kaikkina vuosina merkitsevästi riippuvaisia lajikkeesta. Vuonna 2007 
vehnien valkuaispitoisuudet nousivat yli leipäviljan valkuaispitoisuusvaatimusluokan (12,5\%) Limingan kokeen Bor 03517 -linjaa lukuun ottamatta. Vuonna 2008 kaikki lajikkeet jäivät alle 12,5\% valkuaispitoisuuden Limingassa. Ruukissa ainoastaan Anniina ylitti vaatimusluokan käsittelemättömässä ja alhaisemmassa torjuntakäsittelyssä ja Quarna vain käsittelemättömässä.

Vuonna 2009 valkuaispitoisuudet vaihtelivat Limingassa keskimäärin välillä 12,3-13,3 \%. Ruukissa kaikki lajikkeet ylittivät 12,5 \% vaatimusrajan, paitsi torjumaton linja Bor03026. Parhaimpaan tulokseen pääsi Quarna -lajike, jonka valkuaispitoisuus oli keskimäärin 17,4 (ei torjuntaa) - 16,9 (torjunta) \%. Uusien linjojen alhaisemmat valkuaispitoisuudet voivat osin johtua siitä, että annettu typpiravinne (120 kg) ei riittänyt valkuaisen muodostamiseen. Karjanlanta tai lisälannoitus kasvukaudella olisi voinut nostaa jyvien valkuaispitoisuutta, mutta se ei olisi ollut ympäristötuen ehtojen mukaista.

Vuoden 2009 laatutulokset osoittautuivat erittäin lupaaviksi, joten kokeen vehnien sakoluvut tullaan testaamaan keväällä 2010. Käytännössä on kokemuksia, että hyvissä olosuhteissa PohjoisPohjanmaalla on mahdollista tuottaa myös leipälaatuista vehnää.

\section{Tautitorjunnalla tulosta rehevästä kasvustosta}

Vuonna 2007 vehnäkasvustoissa esiintyi ruskolaikkua (Stagonospora nodorum) sekä vehnänlehtilaikkua eli DTR:ää (Drechslera tritici-repentis). Ruukissa tautitorjunta lisäsi merkitsevästi vehnäsadon määrää (jopa $600 \mathrm{~kg} \mathrm{ha}^{-1}$ ) lämpimänä vuonna 2007. Samana vuonna Limingassa ei kasvitautien torjunnalla ollut tilastollisesti merkitsevää vaikutusta tautien esiintymiseen. Lajikkeella oli erittäin merkitsevä vaikutus tautien määrään molemmissa kokeissa. Kasvitautien torjunta lisäsi vehnän kasvuaikaa merkitsevästi muutaman päivän ainakin Ruukissa, mikä toisaalta aikaisilla ja tautiherkimmillä lajikkeilla, kuten Anniina ja Bor03041, saattoi näkyä selvinä sadonlisäyksinä.

Kesällä 2008 viljoissa esiintyi myös melko runsaasti molempia edellä mainittuja lehtilaikkutauteja. Tautitorjunta vähensi oleellisesti tautien esiintymistä ja yleensä sitä enemmän, mitä taudeille alttiimpi lajike oli kyseessä. Limingassa tauteja esiintyi selvästi eniten Anniinalla ja yleensä vähiten Ainolla ja Quarnalla. Anniina oli myös Ruukissa alttein taudeille, poikkeuksena torjuntataso 0,5 l/ha, jolla Anniinan kasvustoissa oli keskimäärin vähiten tauteja. Aino oli Ruukin kestävin lajike tauteja vastaan. Torjunta-aineen käyttömäärän lisääminen tasosta 0,5 l /ha tasolle 0,8 l /ha ei yleensä vähentänyt vuonna 2008 tautien esiintymistä merkitsevästi.

Kuiva alkukasvukausi vuonna 2009 aiheutti sen, ettei tautitorjunta parantanut vehnien sadontuottokykyä vaan satotasot jopa laskivat Ruukissa. Limingan koeruudulla, jossa kuivuus ei ollut yhtä rajua kuin Ruukissa, kokeen lajikkeet hyötyivät yleensä tautitorjunnasta vuonna 2009. Vehnien tautitorjunta ei tuonut merkitseviä muutoksia hehtolitrapainoihin kummallakaan koealueella.

\section{Yhteenveto}

Vehnän viljely on tulosten perusteella mahdollista joskin riskialtista Pohjois-Pohjanmaalla. Keskimääräinen kasvukausi lämpötilaltaan ja sateiltaan riittää todennäköisesti aikaisimpien lajikkeiden sadonmuodostukselle niin, että sadosta erinomaista ja kauppakelpoista rehun raaka-ainetta. Myöhäisemmille lajikkeille kasvukauden tulee olla jo selkeästi alueen normaalia kasvukautta lämpimämpi ja pitempi etenkin sadon laadun varmistamiseksi.

Tämän koesarjan perusteella kannattaa ottaa viljelyyn kaikkein aikaisempia lajikkeita PohjoisPohjanmaalla ja esimerkiksi vain tietylle osalle tilan peltolohkoista. Kokeiden vehnälajikkeista Anniina oli viljelyvarmin. Siitä saatiin keskimäärin yli 5000 kilon hehtaarisato ja hehtolitrapainot ovat olleet yli 74 kiloa. Alueella käytännön viljelyssä suositusta Quarnasta saatiin keskimäärin 4700 kilon hehtaarisato, mutta hehtolitrapainot jäivät 71 kiloon. Aikaisten lajikkeiden tautitorjunnalla oli yleensä satovastetta, jos tauteja esiintyi runsaasti ja kasvuolosuhteet olivat hyvät. Heikompilaatuiselle vehnälle löytyy myös myyntikanava. Se soveltuu karjan rehuksi, koska on ruokinnalliselta laadultaan suunnilleen ohran tasoista.

Uudet jalostuslinjat osoittautuivat vuonna 2009 viljelyvarmoiksi. Niiden testaus jatkossa pohjoisemmissa olosuhteissa olisi erittäin tärkeää, sillä aikaiset lajikkeet ovat edellytys vehnän viljelyyn IV-kasvillisuusvyöhykkeellä. 